\title{
O DNA: uma sinopse histórica
}

Talles Henrique Gonçalves de Oliveira, Neusa Fernandes dos Santos e Leila Maria

Beltramini

Centro de Biotecnologia Molecular Estrutural (CBME/CEPID/FAPESP)

Instituto de Física de São Carlos - Universidade de São Paulo - São Paulo - Brasil

\begin{abstract}
:
This article aims to describe the most important historical and scientific facts that permitted today's understanding of the structure and functionality of the DNA molecule. We believe that recovering history and divulging it culturally integrates new and old generations to the contemporary society we belong to, facilitating the learning and the understanding about our constitution and functionality, as well as allowing us to speculate about our future, our evolution, the life on our planet, and the focus and course of new research in this scientific area.
\end{abstract}

\section{Resumo:}

Este artigo tem o objetivo de relatar os fatos históricos científicos mais importantes que permitiram o entendimento atual da estrutura e funcionalidade da molécula de DNA. Acreditamos que resgatar a história e divulgá-la integra culturalmente novas e velhas gerações à sociedade contemporânea a que pertencemos, facilitando o aprendizado e a compreensão sobre a nossa constituição e funcionalidade, assim como nos permite especular sobre o nosso futuro, nossa evolução, a vida no planeta, e o enfoque e direcionamento de novas pesquisas desta área científica.

Endereço para correspondência:

Leila Maria Beltramini e-mail: leila@if.sc.usp.br

Centro de Biotecnologia Molecular Estrutural (CBME/CEPID/FAPESP)

Instituto de Física de São Carlos-Universidade de São Paulo

Av. Trabalhador Sãocarlense, 400 CEP: 13560.970 


\section{Construindo o conceito de DNA}

Muitos foram os pesquisadores que direta ou indiretamente contribuíram para elucidar as questões sobre a estrutura e função da molécula de DNA. Podemos voltar no tempo e contar, de forma sucinta, as principais idéias, estudos e influências que foram fundamentais para o entendimento da vida como a conhecemos hoje.

Contemplando a natureza, nos deparamos com uma variedade de seres vivos, que vão desde minúsculas bactérias até gigantescas sequóias. Nesse sentido, torna-se relevante compreender qual a razão pela qual os organismos são tão diferentes, se é que são realmente tão diferentes. Para isso, o mundo científico esperou até 1858, quando Charles Darwin e Alfred Russel Wallace (figuras 1a e 1b), naturalistas ingleses, independente e simultaneamente, apresentaram suas teorias do modo pelo qual algumas espécies evoluem, embora outras pudessem se extinguir [1].

A idéia de que a Terra está em constante transformação ajudou a relacionar os processos da origem das espécies e sua adaptação ao meio ambiente. Darwin analisou criticamente as informações obtidas em suas viagens até que, após 20 anos de catalogação de evidências, publicou seu famoso livro "A origem das espécies por meio da seleção natural" (figura 1c), em 1859, quando foi reconhecido como autor principal dessa teoria [2].

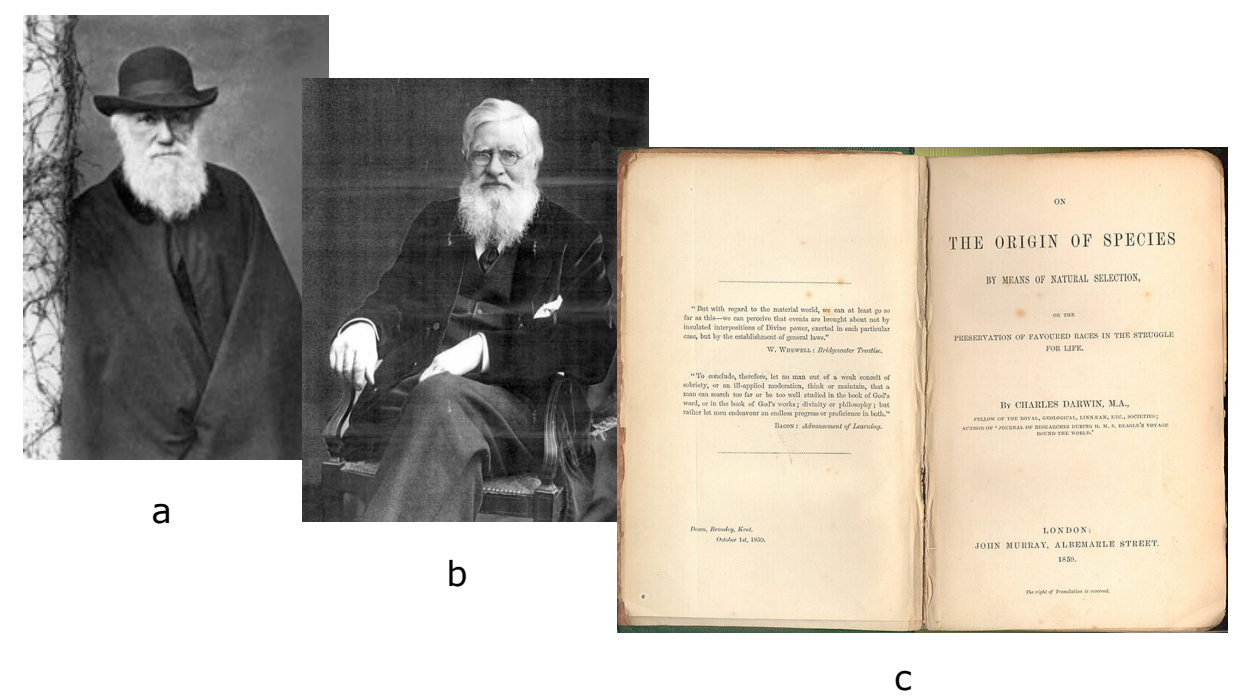

Figura 1: (a) Charles Darwin (1809-1882) ${ }^{1}$; (b) Alfred Russel Wallace (1823-1913) ${ }^{2}$; (c) Foto do livro "A Origem das Espécies por meio da seleção natural" de Darwin ${ }^{3}$.

A teoria de Darwin e Wallace sobre a evolução da vida na Terra revolucionou o modo como o mundo científico e a humanidade compreendiam a existência da vida no planeta [1]. A seleção natural é o processo que permite a transformação gradual de espécies pré-existentes em outras espécies, incluindo a eventual extinção daquelas menos adaptadas às possíveis mudanças ambientais. Os mais aptos ao meio sobrevivem, deixando maior número de descendentes com suas características [3]. A teoria da evolução de Darwin e Wallace, no entanto, não explicava a origem das variedades nem como as características eram transmitidas através das gerações [1]. Somente após a metade do século XIX foram elaboradas as primeiras conclusões acerca da perpetuação das características hereditárias, um feito atribuído ao monge austríaco Gregor Mendel.

\footnotetext{
${ }^{1}$ W. \& D. Downey's Late Victorian Photographs- http://www.rogerco.pwp.blueyonder.co.uk/pixs/downey.htm

${ }^{2}$ James Mallet's home page- http://abacus.gene.ucl.ac.uk/jim/ Mim/Wallace.htm/

${ }^{3}$ University of South Carolina Libraries- http://www.sc.edu/library/spcoll/ nathist/darwin/origin.jpg
} 
Trabalhando no próprio jardim do monastério onde residia (figura 2a), Mendel (figura 2b) descobriu as leis fundamentais da herança genética, deduzindo que os genes - chamados de fatores na época - são unidades distintas herdadas aos pares: um gene paterno e outro materno [4]. Investigou a relação entre a segregação de genes dos progenitores e as características aparentes da prole, como traços dominantes ou recessivos, e reconheceu os padrões matemáticos da herança genética a cada geração [1]. Mendel fez experiências com ervilhas durante oito anos (de 1856 a 1863), mas suas leis e seu trabalho envolvendo a hereditariedade, os quais o tornariam conhecido como o pai da genética, não foram reconhecidos em seu tempo.

Figura 2: (a) Monastério na República Tcheca onde Mendel viveu ; (b) Gregor Mendel (1822$1884)^{5}$.

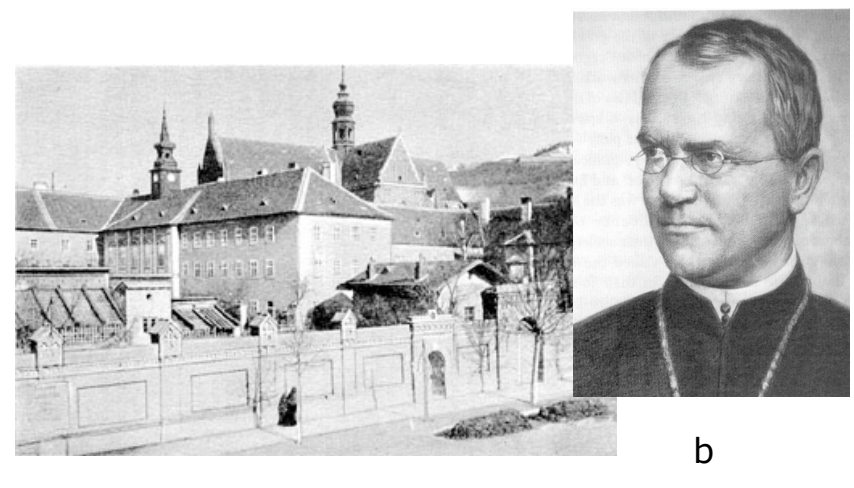

a

Um pesquisador contemporâneo de Mendel chamado Friedrich Miescher (figura 3a), anos mais tarde isolaria a primeira preparação de DNA [5]. Miescher vinha de uma família respeitada que fazia parte da elite intelectual da Basiléia (Suíça). Iniciou seus estudos em medicina, graduando-se em 1868 e dedicando sua carreira à pesquisa (figura 3b). Na Universidade de Tübingen (Alemanha) ele estudou sob a tutela de Felix Hoppe-Seyler.

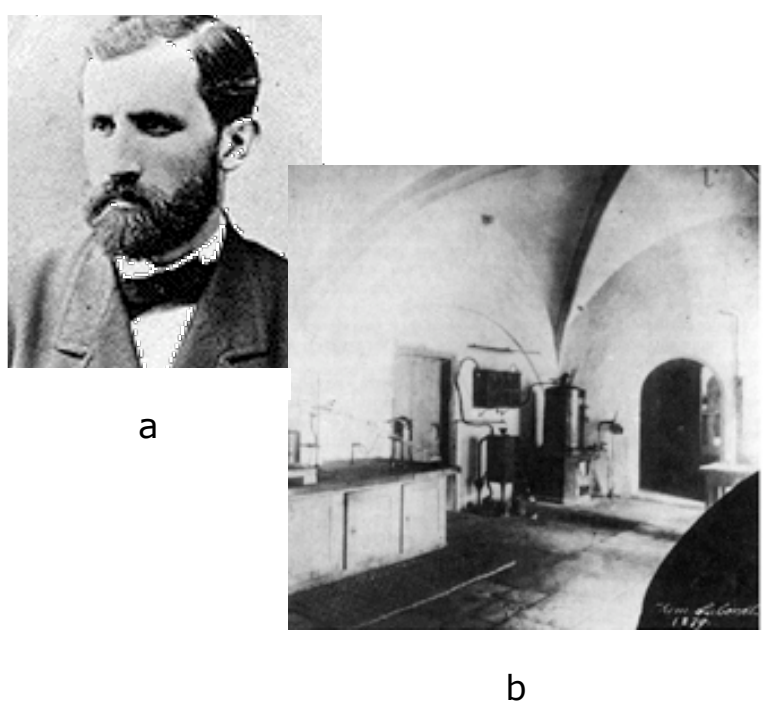

Figura 3: (a) Friedrich Miescher (1844-1895) e (b) o laboratório na Suíça em que trabalhou. ${ }^{6}$
Num tempo em que os cientistas ainda debatiam o conceito de célula, Hoppe-Seyler e sua equipe já eram capazes de isolar moléculas, enquanto a Miescher fora dada a tarefa de investigar a composição dos linfócitos (glóbulos brancos do sangue) [4]. Miescher isolou um tipo de molécula encontrada no núcleo dos linfócitos, a que denominou nucleína, e determinou sua composição química (basicamente oxigênio, nitrogênio e fósforo), adquirindo aos poucos a habilidade de isolá-la de outras células [1].

Embora Friedrich Miescher tivesse concluído grande parte de seu trabalho em 1869, a publicação do artigo só ocorreu em 1871. Ele continuou envolvido no projeto da nucleína até o fim de sua carreira, sem, contudo, estabelecer alguma relação dessa molécula com qualquer fenômeno celular [5].

Desde meados do século XVII até o fim do século XIX, a invenção e o aperfeiçoamento do microscópio vinham propiciando muitas descobertas importantes, pois se iniciaram análises de cortes de animais e vegetais com o uso desse instrumento e, pouco a pouco, a estrutura celular era desvendada [1]. A descoberta de organismos unicelulares mostrou aos cientistas a existência de seres que não possuíam membrana delimitando o núcleo (carioteca), os quais foram denominados procarióticos. Porém, com o uso de corantes adequados, observou-se que

\footnotetext{
${ }^{4}$ Winona State University Biology Department - http://bio. winona.msus.edu/berg

${ }_{5}^{5}$ Margaret H. Peaslee's home page - http://www.upt.pitt.edu/upt_peaslee/current_proj.htm
} 
as demais células dos seres vivos possuem núcleo diferenciado do citoplasma, as chamadas células eucarióticas

Conseqüentemente, em 1838, dois biólogos alemães, Theodor Schwann e Mathias Jakob Schleiden (figuras $4 a$ e 4b), estabeleceram definitivamente a idéia de que todos os seres vivos são formados por células, as menores porções de matéria viva capazes de realizar as diversas funções que mantêm a vida de um organismo [6], enunciando antecipadamente que plantas e animais possuem uma forma de desenvolvimento comum. Era a primeira vez que se oferecia um caminho para explicar a completa estrutura dos seres vivos a partir das propriedades físico-químicas da matéria. No entanto, eles tinham a concepção equivocada de que o surgimento de novas células se dava a partir de agregação dos núcleos celulares (os quais denominavam grânulos), um processo que acreditavam ser regido por forças físicas, essencialmente como ocorre a união de boa parte das moléculas [7].

Assim, o núcleo já não era apenas um detalhe anatômico [7], como havia pioneiramente descrito, em 1831, o botânico escocês Robert Brown (figura 4c), e sim uma importante região celular [8].

Figura 4: (a) Theodor Schwann (1810-1872) e (b) Mathias Jakob Schleiden (1804-1882) ${ }^{7}$; (c) Robert Brown (1773-1858) . $^{8}$

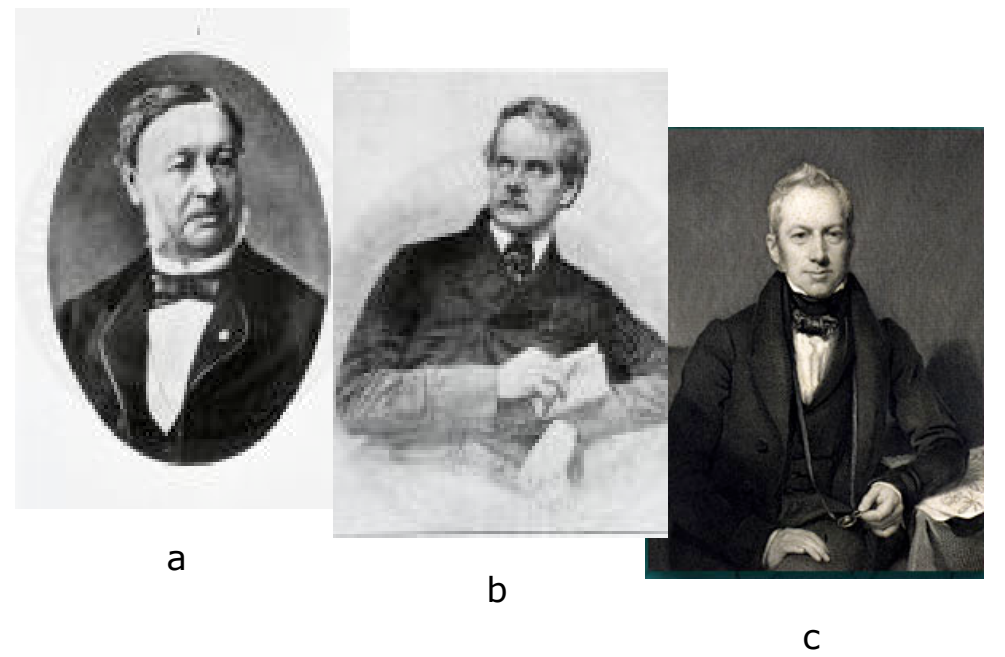

Entre os anos de 1882 e 1885, o alemão Walter Flemming (figura 5a), juntamente com o botânico alemão Eduard Strasburger (figura $5 b$ ) e por meio de estudos de células animais, reconheceu estruturas em forma de bastão dentro do núcleo das células, as quais denominou cromossomos [9]. $\mathrm{Na}$ mesma época, entre 1880 e 1890, o alemão Theodor Boveri (figura $5 \mathrm{c}$ ) fez vários experimentos no campo da citologia e percebeu que o número dos cromossomos das células germinativas se reduzia à metade em um determinado estágio de sua maturação, sendo este um dos primeiros C Figura 5: (a) Walter Flemming (1843-1905) ${ }^{9}$; indícios do processo de meiose [10], processo (b) Eduard Strasburger $(1844-1912)^{10}$; (c). celular que, da mesma forma que a mitose, seria Theodor Boveri $(1862-1915)^{11}$. posteriormente descrito por Walter Flemming. [8].

Com essas descobertas, inferia-se que todos os gametas são células haplóides, ou seja, possuem metade do número de cromossomos das demais células do organismo, e que, durante a fertilização, a união dos dois núcleos gaméticos resulta uma célula-ovo contendo novamente o número completo de cromossomos de uma dada espécie [1].

\footnotetext{
${ }^{6}$ Genetics Group/Biology Department/Faculty of Science/Tarbiat Modares University -

http://www.modares.ac.ir/elearning/mnaderi/Genetic\%20Engineering\%20course\%20II/Pages/gallery5.htm

7 - Enfermería y Fisioterapia de la Universidad de Cádiz - http://www.terra.es/personal/josapa/historia.htm

8 - Awairs NSW- http://awairs.sl.nsw.gov.au/images/flinders/bio/brown.jpg

${ }^{9}$ Genetics Glaxo Smith Kline http://genetics.gsk.com/timeline/flemming.jpg

${ }^{10}$ Biografie-Skizzen von Biologinnen und Biologen http://home.tiscalinet.ch/biografien/images/ strassburger.jpg
} 
Os trabalhos aqui abordados originaram-se de pesquisas em alguns diferentes campos da Biologia, os quais atualmente denominamos Evolução, Genética, Bioquímica e Citologia. É importante enfatizar que, em geral, o conhecimento da época era constituído de contribuições de áreas que não interagiam entre si, pois a comunicação entre os cientistas era bastante restrita. Um bom exemplo disso é que os trabalhos de Mendel foram redescobertos apenas em 1900 pelos botânicos Hugo De Vries, Carl E. Correns e Erich von Tschermak (figura 6).

A partir de então, surgiu o interesse de se determinar a natureza dos fatores mendelianos, ou seja, o que de fato representavam, de que eram constituídos, como agiam e onde se localizavam. Ainda em 1900, um biólogo inglês da Universidade de Cambridge chamado William Bateson (1861-1925) se deparou com um jornal científico contendo um artigo assinado por Hugo de Vries e seus dois colaboradores, relatando as descobertas feitas pelo ainda pouco conhecido Gregor Mendel. Desta forma, Bateson passou a participar de muitos eventos científicos para divulgar tais descobertas, as quais revolucionaram praticamente toda a Biologia desenvolvida posteriormente [4].

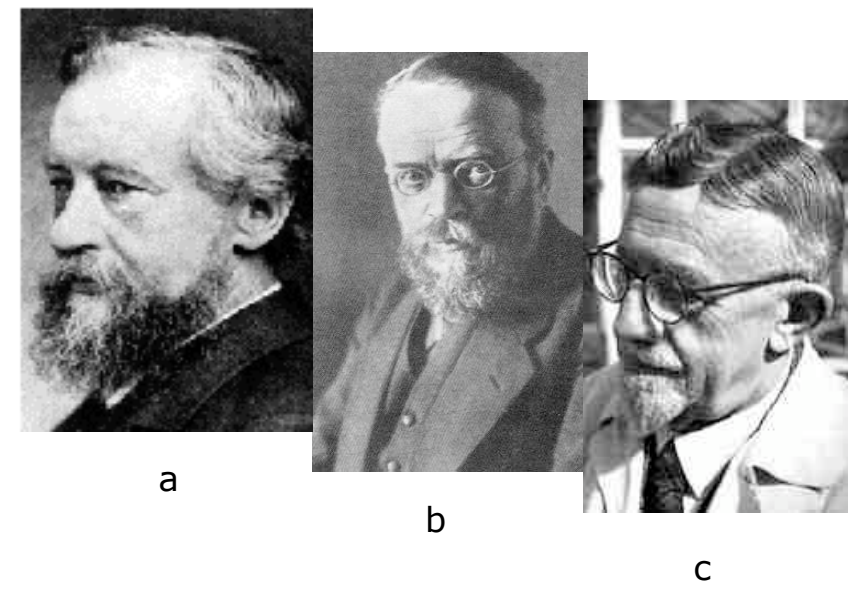

Figura 6: (a) Retrato de Hugo De Vries (18481935) $)^{12}$; (b) Carl E. Correns (1864-1933) ${ }^{13}$; (c) Erich von Tschermak (1871-1962) ${ }^{14}$.

Nota-se que o comportamento dos cromossomos e sua importância eram assuntos promissores durante a virada do século. Tanto, que Theodor Boveri já havia relacionado os cromossomos e a hereditariedade utilizando-se de suas próprias observações experimentais. No entanto, um cientista norte-americano de apenas 25 anos chamado William Sutton (18771916), estudando a meiose de uma espécie de gafanhoto, publicou em 1902 um artigo que mostrava mais claramente as diferenças entre os cromossomos e confirmava a redução do número destes nos gametas durante a meiose. Em 1903, uma outra publicação de sua autoria sumarizava e discutia a importância de suas conclusões e, efetivamente, extraía de forma mais contundente a conexão entre as leis mendelianas e os cromossomos [10]. Mesmo assim, havia muita relutância entre os geneticistas em aceitar essa nova interpretação das leis da hereditariedade.

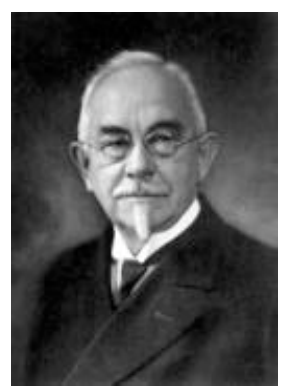

Wilhelm Johannsen (figura 7), um desses geneticistas, rotulava a então recente descrição dos cromossomos como apenas uma "espécie de dialética morfológica", ou seja, um conjunto de idéias com uma lógica puramente aparente, o que mostra a desconfiança do pesquisador com relação à veracidade da nova teoria. O tempo revelou que Johannsen estava errado, mas vale esclarecer que foi ele quem introduziu, em 1909, os termos "gene" para designar a unidade mendeliana antes conhecida como fator, "genótipo" para as características genéticas do indivíduo e "fenótipo" para se referir ao seu aspecto externo [9].

Figura 7: Wilhelm Johannsen $(1857-1927)^{15}$

\footnotetext{
${ }^{11}$ DNA from the Beginning http://www.dnaftb.org/dnaftb/images/8bio.gif

${ }^{12}$ Genetics Group/Biology Department/Faculty of Science/Tarbiat Modares University. http://www.modares.ac.ir/elearning/mnaderi/Genetic\%20 Engineering\%20course\%20II/images/wpe1.gif

${ }^{13}$ Universität Münster -http://www.uni-muenster.de/Rektorat/forschung/bilder/s07e.jpg

${ }^{14}$ Lasker Foundation - http://www.laskerfoundation.org/news/gnn/timeline/images /tschermak.jpg

${ }^{15}$ Rozanski's home page/ http://www.rozanski.gower.pl/ mendelizm2002.htm
} 
Mais tarde, em meados de 1910, Thomas Hunt Morgan (figura 8) e seus colegas de trabalho da Universidade de Harvard observaram que a mosca-das-frutas (Drosophila melanogaster) apresentava gerações com inúmeros indivíduos mutantes, diferindo por características fenotípicas facilmente perceptíveis, como a cor dos olhos, o tamanho e a forma das asas [1]. Analisando-se inúmeros cruzamentos, demonstraram que as moscas se distinguiam umas das outras porque ocorria uma complexa recombinação dos genes a cada nova geração [11].

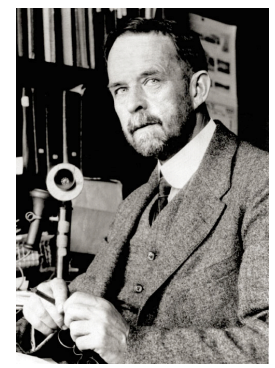

Figura 8: Thomas Hunt Morgan $(1866-1945)^{16}$

Morgan e equipe puderam determinar a localização de vários desses genes nos cromossomos das moscas, publicando, em 1915, o livro "O Mecanismo da Hereditariedade Mendeliana". Morgan estabeleceu a base da genética moderna ao determinar que os genes são regiões do cromossomo responsáveis pelas características inatas de um determinado organismo, o que Ihe valeu o Prêmio Nobel de Medicina de 1933 [12].

Fortalecendo a teoria de que os genes estavam localizados nos cromossomos, Robert Feulgen (1884-1955) demonstrou pelo método de coloração DNA-específico, em 1923, que quase todo DNA celular estava ligado aos cromossomos. Segundo esse método, as zonas mais coradas possuem maior quantidade de DNA. No entanto, nada sugeria que o DNA carregasse toda a informação genética [1], o que tornava qualquer contribuição para o entendimento de suas características algo de fundamental importância.

Na verdade, até a metade do século $X X$, acreditava-se que as proteínas eram responsáveis diretas pela propagação da informação hereditária [13], já que eram as únicas moléculas suficientemente complexas que a comunidade científica julgava necessária para uma função tão importante. Atribuir a natureza química dos genes às proteínas era uma hipótese aceitável. Aceitável até o ano de 1928, quando o conceito de "transformação" surgiu e lançou as evidências de que o material genético é um ácido nucléico. Nesse ano, o médico inglês Frederick Griffith (1877-1941) realizou experiências com bactérias Pneumococcus, causadoras da pneumonia. As bactérias que são envolvidas por uma cobertura de polissacarídeo como proteção apresentam uma superfície externa lisa ( $S$, do inglês, smooth) e são virulentas, ou seja, levam à morte. Existem variações dessas bactérias que, por falha metabólica, não produzem este envoltório externo (são menos virulentas), o que Ihes determina uma aparência externa rugosa $(R)$. Os experimentos mais decisivos consistiram em injetar, num mesmo camundongo, Pneumococcus R vivos e Pneumococcus $\mathrm{S}$ mortos. O interessante é que os camundongos adquiriram a pneumonia letal (oriunda dos Pneumococcus S) e morreram. Para sua surpresa, Griffth ainda encontrou nesses hospedeiros várias colônias dos Pneumococcus $\mathrm{S}$ vivos, concluindo que havia alguma substância nestes que "transformava" os bacilos mais brandos em bacilos fatais. Os pesquisadores contemporâneos de Griffth concluíram que a substância capaz de estimular essa "transformação" deveria ser o material genético dos Pneumococcus S, os quais readquiriam sua virulência. [14].

\footnotetext{
${ }^{16}$ Columbia University http://www.columbia.edu/cu/ alumni/Magazine/images/Fall2002/Morgan.jpg
} 


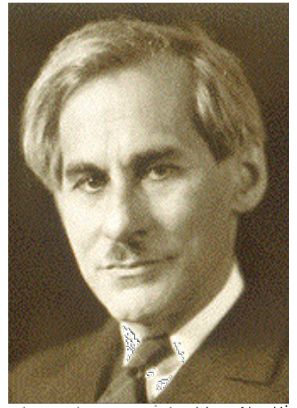

Figura 9: Phoebus Aaron Theodor Levene $(1869-1940)^{17}$
O progresso dos estudos em Biologia Celular vinha revelando a natureza química e funcional de moléculas importantes na organização celular, como é o caso dos ácidos nucléicos, cuja composição química foi determinada pelo cientista russo Phoebus Aaron Theodor Levene (figura 9) [1].

Graduado em medicina em 1892, ele dividia seu tempo entre a prática médica e a pesquisa, começando, já em 1894, a publicar artigos sobre a estrutura química de açúcares. Em 1905, é empregado no Instituto Rockefeller (EUA), onde estuda a estrutura química dos ácidos nucléicos. Em 1931, identifica seus componentes básicos (bases nitrogenadas, açúcar e fosfato) e demonstra que estes são polímeros, ou seja, formados por muitas repetições de uma mesma subunidade [1].

Levene também estabeleceu a diferença química entre os dois ácidos nucléicos, o DNA e o RNA, termos que começaram a ser largamente utilizados. No entanto, Levene morreu em 1940, antes que o significado dessas moléculas fosse esclarecido [15].

No início do século $X X$, os cientistas começavam a determinar a natureza e a causa das doenças, o que atraía o jovem médico canadense Oswald Theodore Avery (figura 10) [1]. Em 1907, Avery se integrou ao Laboratório de Hoagland (Nova Iorque), o primeiro laboratório de pesquisas bacterianas dos Estados Unidos, realizando trabalhos com aplicação de diferentes métodos químicos e imunológicos [16]. Em 1913, graças a um artigo publicado envolvendo a bactéria causadora da tuberculose, Avery é convidado a trabalhar no Instituto Rockefeller, onde estudaria as bactérias Pneumococos até sua aposentadoria, em 1948 [17].

Pouco antes de seu afastamento definitivo, por volta de 1944, um grupo de cientistas sob sua coordenação, com base no experimento de Frederick Griffth, separou moléculas de DNA, RNA, carboidratos e lipídios, repetindo os mesmos procedimentos de inoculação de bactérias em camundongos.

Feito isso, pôde-se verificar que apenas a amostra contendo DNA foi capaz de transformar as bactérias, conferindo-Ihes a patogenia. A fração de DNA mantinha sua capacidade transformante mesmo quando tratada com diversas enzimas específicas para clivar proteínas (proteases) ou ao ser aquecida. Contudo, o mesmo não acontecia após o tratamento com enzimas específicas para clivar o DNA (as DNAses). Tais dados evidenciaram que o DNA, e não as proteínas, era a molécula capaz de transformar bactérias não patogênicas, comprovando o fato de que a informação genética é armazenada no DNA [1].

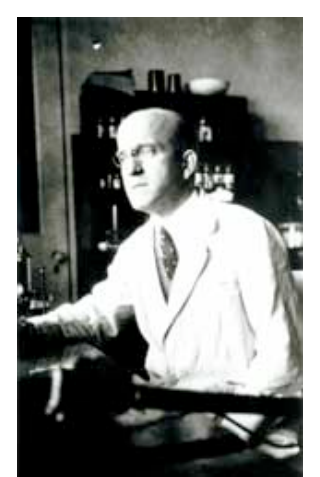

Figura 10: Oswald Theodore Avery (1877$1955)^{18}$

Oito anos mais tarde, a suposição de que o DNA é o material genético foi reforçada pelo clássico "experimento do liquidificador" de Alfred Hershey (figura 11a) e Martha Chase (figura 11b). Neste caso, foram marcadas duas culturas de fagos (vírus que infectam bactérias): uma com fosfato radioativo (o qual se incorporava ao DNA) e uma com enxofre radioativo (o qual se incorporava às proteínas).

\footnotetext{
${ }^{17}$ Genetics Group/Biology Department/Faculty of Science/Tarbiat Modares University http://www.modares.ac.ir/elearning/mnaderi/Genetic\%20 Engineering\% 20course\%20II/images/15bbio.gif

${ }^{18}$ Genome News Network - http://www.genomenewsnetwork.org/gnn_images/timeline/pictures/avery.jpg
} 


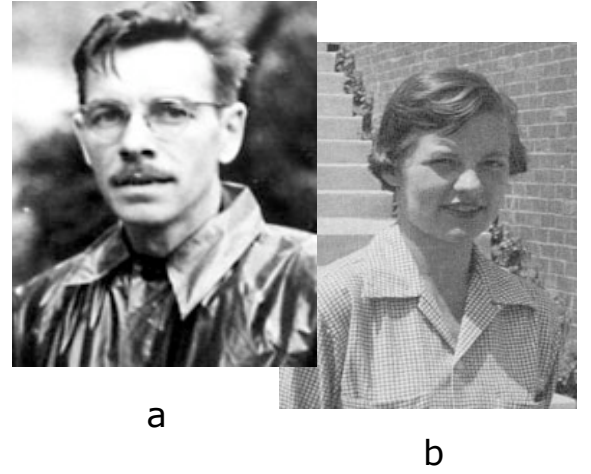

Figura 11: (a) Alfred Hershey $(1908-1997)^{19}$; (b) Martha Chase $(1930-)^{20}$.
Foram incubadas bactérias $E$. coli com os fagos marcados e agitadas as amostras em um liquidificador, de forma que as cápsulas dos fagos fossem separadas das bactérias. Em seguida, as culturas foram centrifugadas para que as cápsulas virais ficassem no sobrenadante e as bactérias no precipitado. Com isso, foi possível uma constatação importante: grande parte do fosfato fora encontrado no precitado, enquanto a maior parte da fração protéica (contendo enxofre) estava no sobrenadante [15]. Logo, Hershey e Chase concluíram que era justamente o DNA, e não as proteínas, o que penetrava nas bactérias e, por isso, era o agente responsável pela multiplicação viral. Este fato veio comprovar a importância do papel desempenhado pelo DNA na hereditariedade, embora a comunidade acadêmica em geral ainda se mostrasse um pouco relutante em considerar que tal molécula fosse capaz de trazer consigo a informação genética [13].

Na verdade, nada se sabia sobre como os genes transmitem as características às gerações de seres vivos, bem como qual era a estrutura completa do DNA [1], ou seja, como essa molécula se organizava no espaço.

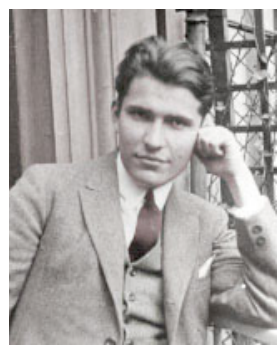

Figura 12: Erwin Chargaff (1905$1995)^{21}$
Erwin Chargaff (figura 12), um austríaco e bioquímico da Universidade de Columbia [16], Nova Iorque, havia analisado em 1949 vários exemplares de organismos (bactérias, vertebrados, plantas superiores etc) pelo método da cromatografia desenvolvido após a segunda guerra mundial. Com base nessa técnica, ele verificou que existe uma relação quantitativa entre as bases nitrogenadas constituintes do DNA dos diferentes seres vivos estudados: a quantidade da base púrica adenina $(A)$ era proporcional à base pirimídica timina $(T)$, observandose o mesmo para guanina (G) e citosina (C). Chargaff especulou que suas constatações talvez pudessem ter significado mais profundo, não ousando qualquer afirmação conclusiva [13].

Além disso, Alexander Robertus Todd (figura 13), um famoso químico orgânico de Cambridge e prêmio Nobel de Química em 1957 [8], daria sua contribuição no início da década de 50 ao estudar minuciosamente os nucleosídeos (base nitrogenada ligada quimicamente a um açúcar) e concluir que estes estavam unidos a grupos fosfatos nas posições 3 'e $5^{`}$ das moléculas de desoxirribose, o açúcar do DNA. Essas ligações recebiam a denominação de ligações fosfodiéster [12]. No entanto, o impasse com relação ao mecanismo da hereditariedade perdurou até 1953, ano da publicação do trabalho que descrevia a estrutura molecular do DNA [1].

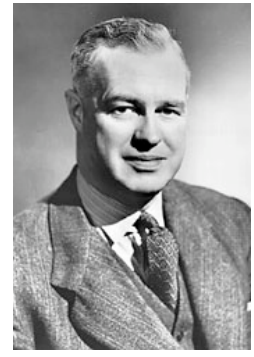

Figura 13: Alexander Robertus Todd (1907$1997)^{22}$

\section{DNA: Afinal o que é isso?}

Se quisermos compreender como James Watson (figura 14a) e Francis Crick (figura 14b) elucidaram a estrutura do DNA devemos nos recordar que, ao longo dos anos, diversas foram as contribuições de cientistas que os precederam e, com seus estudos, possibilitaram a tão aclamada descoberta. Além disso, é preciso compreender quais eram os anseios que

\footnotetext{
${ }^{19}$ Cold Spring Harbor Laboratory/ http://www.cshl.edu/public/gifs/hershey.jpg

${ }^{20}$ Linus Pauling and the race for DNA- http://osulibrary.orst.edu/specialcollections/coll/pauling/dna/pictures/portraitchase.jpg

${ }^{21}$ Linus Pauling and the race for DNA -

http://osulibrary.orst.edu/specialcollections/coll/pauling/dna/narrative/images/chargaff.jpg

${ }^{22}$ Encyclopædia Britannica- http://www.britannica.com/nobel/art/otoddof002p1.jpg
} 
motivaram a dupla a se dedicar a esse tema. Como já dissemos, o meio científico atribuía às proteínas o papel de difusão das características hereditárias. Para isso, afirmavam que as proteínas eram as únicas biomoléculas satisfatoriamente complexas que poderiam representar as inúmeras possibilidades genéticas observadas. Por outro lado, experimentos como os de Avery, e Hershey e Chase demonstravam a intrínseca relação entre o DNA e o material genético [13].

Em 1951, contando então com vinte e dois anos, o biólogo americano James Dewey Watson iniciou sua carreira científica em Copenhague (Dinamarca) sob a tutela de Herman Kalckar, que pesquisava o comportamento dos nucleotídeos, unidades básicas dos ácidos nucléicos. Contudo, a bioquímica tradicional com que se trabalhava na época não o seduzia, de forma que na sua concepção, o problema da base química da hereditariedade poderia ser solucionado através de outros recursos.

Por ocasião de um congresso ocorrido em Nápoles (Itália) sobre a estrutura de macromoléculas, Watson observou as imagens de difração de raios $X$ de uma amostra de DNA pela primeira vez, o que lhe revelou uma certa regularidade desse ácido nucléico e o fez perceber que o material genético poderia ser analisado de forma racional. O conferencista deste evento era um físico chamado Wilkins, professor do King's College, de Londres.

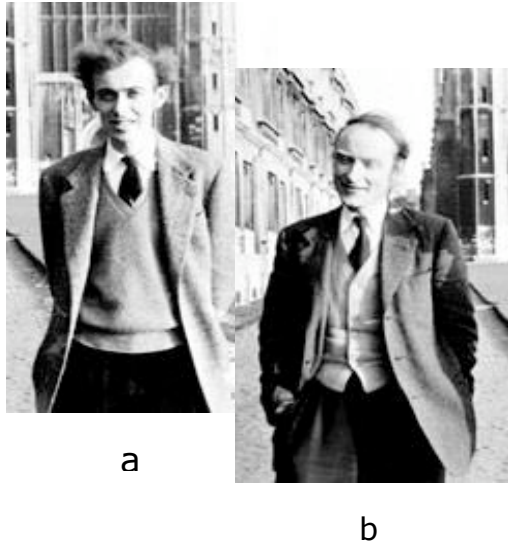

Figura 14: (a) James Watson (1928 - ) e (b) Francis Crick $(1916-)^{23}$.

Maurice Hugh Frederick Wilkins (figura 15a) havia obtido um preparado de DNA de ótima qualidade extraído do timo de bezerros e, por acaso, pôde verificar que apareciam longos filamentos distendidos quando se tocava a solução viscosa de DNA com um bastão. A partir deste material foram tiradas as melhores fotos daquele período, mas que ainda não possibilitavam sentenciar qual era a estrutura do DNA. Watson, interessado em mais conhecimentos nesta área, procurou Wilkins para que pudesse integrar seu grupo de pesquisa, não obtendo sucesso em sua tentativa. Então, por meio de contatos com alguns pesquisadores influentes, Watson conseguiu ser transferido para o laboratório Cavendish (figura 15b), em Cambridge, sob a tutela de Max Ferdinand Perutz (figura 15c), o qual dedicava-se à análise estrutural da hemoglobina (proteína que transporta oxigênio no sangue) por difração de raios $\mathrm{X}[13]$.

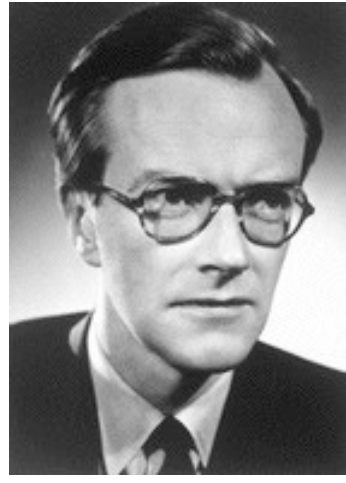

a

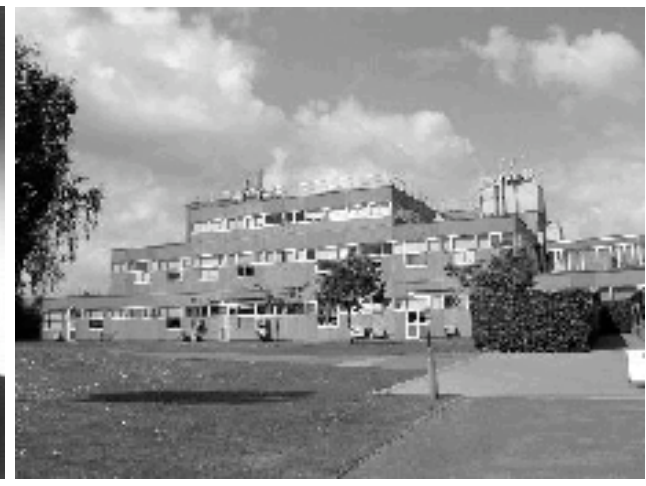

b

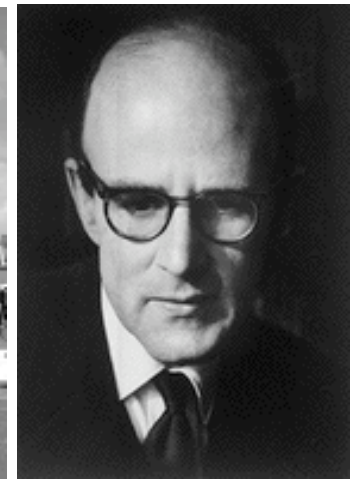

C

Figura 15: (a) Maurice Wilkins (1916- $)^{24}$; (b) Laboratório Cavendish, Cambridge, Inglaterra ${ }^{25}$; (c) Max Perutz $(1914-2002)^{26}$.

\footnotetext{
23 - Genetics Group/Biology Department/Faculty of Science/Tarbiat Modares University- http://www.modares.ac.ir/ elearning/mnaderi/Genetic\%20Engineering\%20course\%20II/images/tea_br1.jpg

${ }_{24}$ Moderm Science and the Mind -http://www.consciousness.arizona.edu/modernsci/presLecture1_files/mwilkins.jpg

${ }^{25}$ Cambridge 2000: photos of Cambridge, England -

http://www.cambridge2000.com/cambridge2000/images/0007/P7281916.jpg

${ }^{26}$ Nobel Museum - http://www.nobel.se/chemistry/laureates/1962/perutz-bio.html
} 
Nesse laboratório aconteceria o encontro decisivo entre Watson e Francis Harry Compton Crick, co-autor na publicação científica que aconteceria em 1953. Crick era físico e havia trabalhado como desenhista de minas magnéticas marinhas durante a segunda guerra mundial, dando continuidade ao seu doutorado (sob a orientação de Max Perutz) após 1945 [12]. Do mesmo modo que Watson, Crick mostrava-se muito interessado pela idéia de poder interpretar complexos processos biológicos utilizando ferramentas e métodos das ciências exatas. Nesse sentido, ambos precisariam conhecer um pouco mais sobre moléculas imprescindíveis à biologia celular: as proteínas.

Justamente por esse motivo, eles procuraram um grupo que reunia os recursos humanos ideais para o aprofundamento do conhecimento nessa área, visto que Max Perutz, o chefe do laboratório, era um especialista na produção de imagens da hemoglobina via raios X. Mas como várias dessas imagens eram difíceis de serem analisadas devido aos infindáveis detalhes moleculares, Crick percebeu rapidamente que o problema deveria ser atacado de uma forma mais abrangente, idéia esta que somente era compartilhada pelo recém chegado James Watson. Crick com 35 anos, e Watson com 23, pareciam tomados pelo mesmo pensamento com relação à biologia molecular: priorizar o essencial: descobrir o mecanismo através do qual os seres vivos, perpetuam geneticamente seus caracteres. A partir daí, ambos iniciaram um trabalho conjunto que visava elucidar a estrutura do DNA.

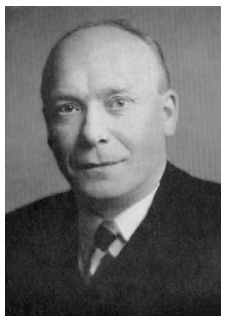

Figura 16: William Astbury (1898-1961)
O primeiro empecilho a este plano, no entanto, era o fato de oficialmente cada um deles já possuir um projeto específico a ser desenvolvido no laboratório, além de precisarem de um bom preparado de DNA com o qual pudessem trabalhar (recurso que na época não Ihes era disponível) [13]. A saída foi recorrer a diagramas datados de 1938 que continham imagens de raios $X$ do DNA obtidas por William Astbury (figura 16), o qual também havia utilizado essa técnica produzindo imagens de outros materiais [13]. Embora tais imagens não fornecessem detalhes suficientes do arranjo molecular do DNA, era possível perceber um certo empilhamento dos nucleotídeos, evidenciado pela distância periódica de 3,4 $\AA$ entre estes [5].

Ao chegar ao laboratório do King's College para trabalhar em parceria com Maurice Wilkins, uma experiente rádio-cristalógrafa chamada Rosalind Elsie Franklin (figura 17a) obteve melhores imagens do DNA por difração de raios X (figura 17b) [18].

Figura 17: (a) Rosalind Elsie Franklin (1920-1958) (b) Imagens de difração de raio $x$ do $D_{N A}^{29}$.

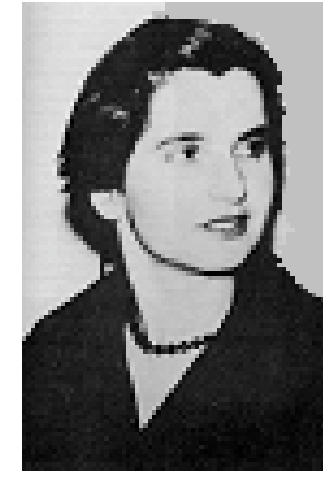

a

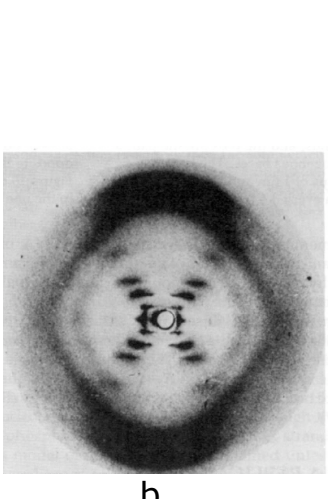

b

Na realidade, a análise física da estrutura do DNA já havia sido pioneiramente delineada um pouco antes, em 1944, data da publicação do livro "What is Life?" (O que é vida?) pelo físico austríaco Erwin Schrödinger (figuras 18a e 18b).

\footnotetext{
${ }^{27}$ Linus Pauling and the race for DNA- http://osulibrary.orst.edu/specialcollections/coll/pauling/dna/pictures/portraitastbury.jpg

${ }^{28}$ - Contributions of $20^{\text {th }}$ Century Women to Phisics- http://www.physics.ucla.edu/ cwp/images/franklin/franklin1.jpg ${ }^{29}$ - Science In The News - Genetic

Engineering/http://enative.narod.ru/practice/voa/jpg/uwinnipeg.ca_rosalind_franklin_x-

ray_picture_dna_3march03_se.jpeg
} 
Embora ele erroneamente concebesse o gene como uma grande molécula protéica, seu livro influenciou significativamente as pesquisas nessa área, já que sua argumentação baseava-se nos aspectos quânticos e termodinâmicos da matéria. Em linhas gerais, ele tinha a concepção de que a conservação dos genes através das gerações só poderia ser explicada se estes consistissem de moléculas dispostas em sólidas redes tridimensionais: os cristais. Esses agregados, no caso do DNA, seriam formados por diferentes grupos de átomos não repetitivos com função própria, razão pela qual os denominou cristais aperiódicos [19].

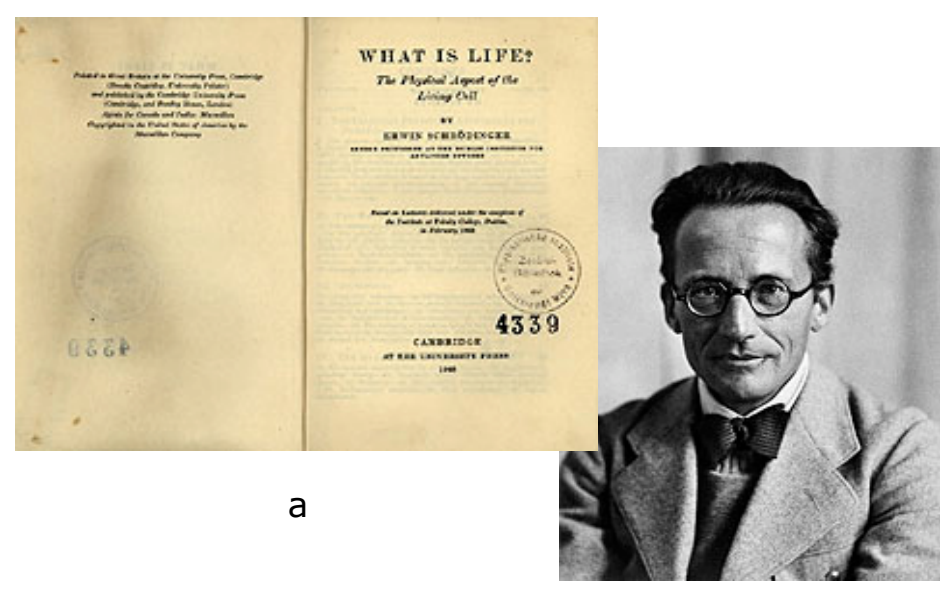

b

Figura 18: (a) Livro "What is Life?"30; (b) Erwin Schrödinger (1887-1961) ${ }^{31}$.

Desse modo, algumas especulações mais ousadas já vinham sendo feitas a respeito da estrutura desses cristais, como por exemplo a dedução da existência de um filamento molecular duplo ou triplo, pois o conhecido valor de sua densidade impossibilitava a idéia de existir uma cadeia simples; estruturas de filamentos simples teriam densidades menores devido ao maior volume ocupado [13].

Watson teve acesso a diagramas das difrações de raios $X$ de Rosalind em um seminário apresentado por ela no final de 1951, onde eram encontradas boas indicações das dimensões da molécula de DNA [12]. Apesar destas informações terem sido reunidas de forma incompleta e pouco criteriosa por Watson, estas viabilizaram a construção do primeiro modelo apresentado pela dupla Crick-Watson aos colegas do King's College, iniciativa que infelizmente resultara num grande infortúnio, uma vez que o modelo fracassara.

Mal superado o equívoco ocorrido em dezembro de 1951, Watson e Crick imediatamente foram proibidos de trabalhar com DNA, medida que os obrigava a se dedicarem aos seus trabalhos de doutorado. Crick voltava-se à estrutura da hemoglobina e Watson à análise por difração de raios $\mathrm{X}$ do vírus do mosaico do tabaco.

Paralelamente a esses fatos, o químico americano Linus Pauling (figura 19a), no Instituto de Tecnologia da Califórnia (Caltech) em Pasadena, Estados Unidos (figura 19b), também se confrontava com o problema da estrutura do DNA. Entretanto, para ele o DNA seria apenas mais uma biomolécula importante na maquinaria celular, não atentando para sua função primordial: a transmissão da informação genética. Da mesma forma que acontecia com Crick e Watson, Pauling não dispunha de bons preparados de DNA, bem como da técnica necessária para a análise deste material. Também se limitando aos diagramas de Astbury, ele e seu amigo Robert Corey (figura 19c) aventuraram-se à produção de um modelo estrutural [13].

\footnotetext{
${ }^{30}$ Zentralbibliothek für Physik- http://www.zbp.univie.ac.at/ schrodinger/images/Was\%20ist\%20Leben\%20(1)250.JPG

${ }^{31}$-Be more PBS- http://www.pbs.org/wgbh/nova/photo51/images/befo-schroedinger.jpg.
} 


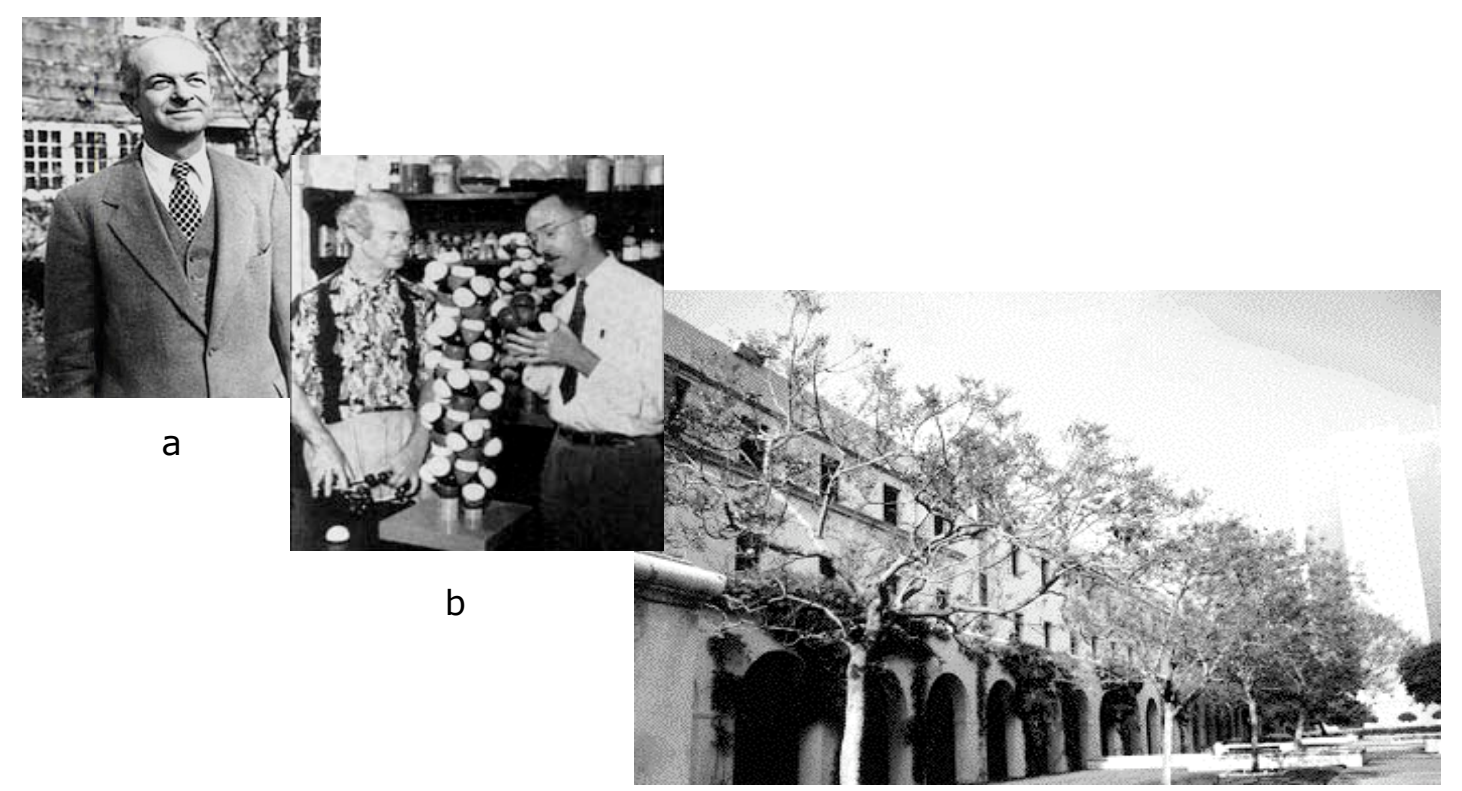

Figura 19: (a) Linus Pauling (1901-1994) ${ }^{32}$; (b) Linus Pauling e Kodert Corey $(1897-1971)^{33}$; (c) Instituto de Tecnologia da Califórnia, Pasadena, Estados Unidos ${ }^{34}$.

Cientes desta pesquisa paralela, Watson e Crick temeram pela perda do reconhecimento da tão sonhada descoberta, afinal o sucesso da estrutura protéica em $\alpha$-hélice descoberta por Pauling o indicava como futuro ganhador do Nobel. No entanto, depois de ler a cópia do trabalho realizado por Pauling, perceberam que mesmo estando de acordo com as antigas imagens de Astbury e ser uma estrutura concebível em três dimensões, aquele modelo não era capaz de explicar a relação do DNA com os genes [1]. Segundo o modelo de Pauling, o DNA seria formado por três filamentos de polinucleotídeos enroscados entre si, estando o eixo de açúcar-fosfato no meio e as bases nitrogenadas livres na parte externa. Particularmente, essa última característica demonstrava-se um tanto incoerente, pois as bases na periferia prediziam a um ácido características básicas, além de que se os fosfatos ocupassem o interior da molécula, haveria incompatibilidade (repulsão) entre as suas cargas [13]. Um outro aspecto que não fora levado em conta no modelo de Pauling trata-se da proporção quantitativa entre as bases timina e adenina, bem como entre guanina e citosina [16]. Ainda assim, a publicação de Pauling tinha um certo peso, o que poderia comprometer o mérito da almejada descoberta de Watson e Crick, mas que, ao mesmo tempo, dava-Ihes impulso para a retomada de suas pesquisas sobre o DNA.

A princípio, eles se fixaram nas informações químicas obtidas por Chargaff sobre a proporcionalidade das bases nitrogenadas, e por Alexander Todd, acerca das ligações fosfodiéster. Como Watson e Crick não conheciam as fórmulas químicas das bases nitrogenadas, foi preciso que David Donohue, numa visita ao laboratório Cavendish, partilhasse de sua experiência no Caltech, onde fora orientado por Linus Pauling, ensinandoIhes as fórmulas corretas [13].

O segundo ponto de grande interesse foi o trabalho com difração de raios $X$ do DNA desenvolvido por Rosalind Franklin, o qual contribuiu de forma crucial para a solução da estrutura do DNA por demonstrar a existência de dois estados da molécula, definir as condições de transição desses estados e sugerir que os grupos fosfatos se situavam externamente à molécula [1]. Suas imagens forneciam boas pistas sobre o arranjo tridimensional atômico dos agregados cristalinos de DNA, mas, apesar disso, não ofereciam

\footnotetext{
${ }^{32}$ Celebrity websites/http://www.linus-pauling.com/pauling.jpg

${ }^{33}$ Linus Pauling and the race for DNA- http://osulibrary.orst.edu/

specialcollections/coll/pauling/dna/narrative/images/paulingcorey.jpg

${ }^{34}$ Department of Knowledge-based Information Engineering home page -

http://www.tutkie.tut.ac.jp/ mich/caltech.bulding.gif
} 
dados conclusivos. Franklin era demasiadamente cuidadosa e cética, características que não motivaram-na a engendrar teorias no campo da Biologia, embora o segredo dos genes constituísse um grande desafio na época. Isso não significava que suas descrições do DNA estavam totalmente disponíveis, haja vista seu desapontamento com Max Perutz quando este, sem consultá-la, forneceu seu relatório para a apreciação de Crick e Watson [13]. Nele havia informações sobre o diâmetro da espiral ( $20 \AA$ ), a distância de $3,4 \AA$ entre as bases dispostas paralelamente ao eixo helicoidal, o valor da altura de um giro da espiral cristalizada ( $34 \AA$ ) e a informação de que se o eixo da molécula sofresse um giro de $180^{\circ}$, a imagem evidenciada pela difração seria a mesma. Além disso, como havia sido exposto no seminário ocorrido no final de 1951, a densidade do material indicava haver mais de uma cadeia peptídica formando a molécula [20].

O terceiro e mais decisivo aspecto considerado foi, finalmente, a criação de modelos representativos da molécula de DNA, estratégia mais uma vez influenciada por Linus Pauling [13], o qual utilizara modelos de papel para desvendar a estrutura em alfa-hélice de polipeptídios [12]. O método consistia na construção de objetos feitos de papel ou arame cujas dimensões e formas procuravam simular a disposição dos átomos e os ângulos das ligações encontradas, trazendo a vantagem de se poder manipular qualquer estrutura tridimensional. A escolha do trabalho manual, em detrimento do esforço intelectual, era freqüentemente ironizada por muitos cientistas, sabendo-se que a priori era possível calcular matematicamente todas as coordenadas de um modelo. Com efeito, a eficácia dos modelos se revelava quando, ganhando a forma desejada, estes apontavam erros em cálculos que levavam meses para elucidar estruturas moleculares [13].

Como a encomenda dos modelos de arame demorava a ser entregue pela oficina do instituto, Watson e Crick fizeram protótipos de modelos das bases por meio de recortes de papel e, detidos pelo interesse nesses recortes, perceberam que a figura de $G$ moldava-se à figura de C, assim como a de A se adaptava precisamente à de $T$, além dos pares evidenciarem perfis muito parecidos. Após a entrega dos modelos de arame, Crick e Watson iniciaram a construção de um modelo molecular que atingiria dois metros de altura, mostrando duas cadeias polinucleotídicas antiparalelas ligadas por pontes de hidrogênio e dispostas de forma helicoidal. Sendo auto-explicativa, a estrutura concebida mostrava de forma compreensível que o DNA era realmente o verdadeiro transmissor das informações genéticas, em oposição à idéia de que as proteínas possuíam essa função [1].

Em 1953, publicaram seus resultados Francis Crick, James Watson [21], Maurice Wilkins, Rosalind Franklin e seu doutorando, Raymond Gosling, que foram os responsáveis diretos pela descoberta. Nesses trabalhos, encontramos o modelo estrutural de Watson e Crick, os dados provenientes da difração de raios X obtidos por Franklin e Gosling, e uma discussão de outros três cientistas que atestava estar o dúplex de DNA em conformidade com as imagens obtidas via raios $X$ [13]. No mesmo ano, Watson e Crick registraram num outro artigo hipóteses sobre as conseqüências da descoberta para a Genética, conjeturando, por exemplo, que as mutações ocorridas nos genes eram devido aos erros de pareamento entre as bases nitrogenadas [22]. Nessa ocasião, a seqüência dos nomes dos autores na publicação original foi decidida por cara ou coroa [13]. No tocante à duplicação do DNA, eles se dividiram entre a possibilidade desta acontecer independentemente ou pela ação enzimática. Futuramente, Crick assumiria: "Nossa incapacidade de imaginar que a função das enzimas era essencial demonstra como o nosso conhecimento da Biologia Molecular era falho".

Naquela época, a publicação destes trabalhos não teve um impacto significante sobre a comunidade científica. Prova disso é que a estrutura espacial proposta por Watson e Crick foi citada sumariamente nos artigos de revisão sobre ácidos nucléicos de forma descontextualizada, no meio ou no fim dos textos. Anos mais tarde, a extensão e profundidade da descoberta seriam finalmente reconhecidas, fato que se deve muito à colaboração de Max Delbrück, pesquisador que difundia tais artigos em vários simpósios. O próprio Delbrück, que se interessava por assuntos nessa área, admitiu que os próximos resultados em Biologia Molecular, por mais interessantes que fossem, seriam apenas detalhes derivados da fundamental descoberta da dupla hélice [13]. 
A partir daí, James Watson passou a estudar o RNA, embora sem dar grandes contribuições nessa área, foi administrador do Cold Spring Habor Laboratory e um eminente autor de livros didáticos. No ano de 1988, chefiou o projeto mundial de seqüenciamento do genoma humano, entregando o cargo quatro anos depois. Francis Crick, por sua vez, ocupou papel importante no desenvolvimento da Biologia Molecular até o final da década de 60, quando iniciou pesquisas envolvendo a atividade cerebral [12]. A Maurice Wilkins ficou a incumbência de estabelecer precisamente as coordenadas atômicas do modelo descoberto. Fato que de certa forma o situava numa posição de menor importância, mas que the daria o mesmo Nobel entregue a Crick e Watson [13]. O mesmo não aconteceu com a jovem Rosalind que, como grande parte da comunidade científica da época, desconhecia os efeitos prejudiciais da radiação. Devido a isso, faleceu aos 35 anos de idade em 1955, ou seja, antes da entrega do prêmio ocorrida em 1962 [1].

Em suma, o esclarecimento da estrutura helicoidal dupla do DNA foi, e ainda continua a ser, uma das descobertas mais expressivas da história da Biologia [4]. Como se isso não bastasse, era relativamente fácil entender tal modelo, visto que a informação genética é codificada por nada mais que quatro diferentes bases nitrogenadas. Quanto à replicação, poderia ser explicada pela separação das duas fitas antiparalelas e subseqüente síntese de novas cadeias polinucleotídicas complementares, mostrando que Watson e Crick decifraram o que se poderia acertadamente chamar de "um dos principais segredos da vida" [13].

Embora o homem tenha avançado muito no campo do conhecimento, um dos grandes desafios dos cientistas é compreender o mecanismo exato da vida. A célebre publicação de 1953 na revista "Nature" (figura 20), sobre a elucidação da estrutura do DNA como veículo da hereditariedade conduziu a uma explosão do conhecimento desta nova área que surgia, a Biologia Molecular, validando a visão de que os seres vivos são sistemas altamente organizados, compostos por células que, por sua vez, são compostas por moléculas e frutos de um longo processo de evolução.

O seqüênciamento, o isolamento, a clonagem de genes, a organização e a detecção de alterações do genoma, o desenvolvimento de organismos transgênicos, o isolamento e purificação de outras biomoléculas e determinação da estrutura de proteínas representam algumas das inúmeras questões que só foram detectadas e/ou esclarecidas através de metodologias que esta ciência desenvolveu com o intuito de desvendar a vida e aperfeiçoá-la, e que vieram impulsionar as pesquisas de várias outras áreas do conhecimento. Enfim, A Biologia Molecular nasceu influenciada pelos avanços da Genética e da Bioquímica, sugerindo que esta deverá ser, em potencial, a principal Ciência do século XXI [23]. 
No. 4356 April 25, 1953

equipment, and to Dr. G. E. R. Deacon and the esptain and officers of R.R.S. Discovery II for their part in making the observations.

'Young, F. B., Gerrard, H., and Jevons, W., Pkil, Nag., w, 140

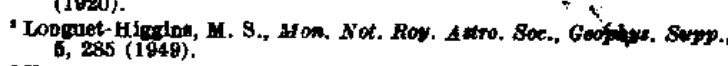

- Von Arz, F. S.. Woods Hole Papers in Phys. Ocearoc. Meteor., 11 th.

\section{MOLECULAR STRUCTURE OF NUCLEIC ACIDS}

\section{A Structure for Deoxyribose Nucleic Acid}

WE wish to suggest a structure for the salt W deoxyribose nucleic acid (D.N.A.). This structure has novel features which are of considerable biological interest.

A atructure for nucleic acid has already been proposed by Pauling and Corey'. They kindly made their manuseript available to us in advance of publication. Their model consists of three intertwined chains, with the phosphatee near the fibre axis, and the bases on the outside. In our opinion, this structure is unsatisfactory for two reasons (1) Wo believe that the material which gives the $\mathrm{X}$-ray diagrams is the salt, not the free acid. Without the soidio hydrogen atoms it is not olear what forces would hold the structure together, especially as the negatively 'charged phoephates near the axis will repel each other. (2) Some of the van der Wadis distences eppear to be too ernall.

Another three-chsin structure has also been sug gested by Fraser (in the press). In his model the phosphates are on the outside and the bases on the inside, linked together by hydrogen bonds. This structure as described is rather ill-defined, and for this reason we ghall not comment on it.

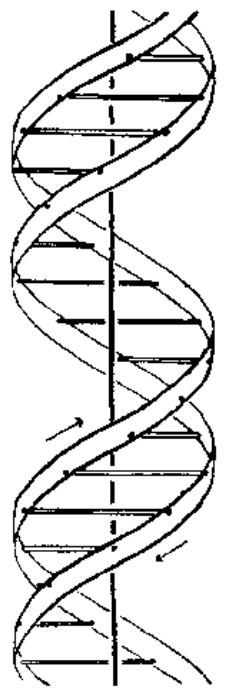

We wish to put forward o redically different structure for the selt of deoryribose nucleic acid. This structure has two helical chaing asch coiled round the same axis (soo diagram). We have made the nsual chemice sesumptions, nermely, that each chain. consista of phosphate diester -groups joining B-D-deoxyribrofurenose residues with $3^{\prime}, 5$ linkages. The two chains (but not their bases) are related by a dyed perpendicular to the fibre axis. Both chains follow righthanded helioes, but owing to the dyad the quences of the atoms in the two cheing rum in opposite directions. Each chain loosely resembles Furberg' $\mathrm{s}^{2}$ model No. 1; thet is, the bases are on the inside of the helix and the phosphstes on the outside. The configuration of the sugar and the atoms near it is close to Furberg's 'Btandard configuration', the sugar being roughly perpendicular to the attached bese. There is a residue on each chain every $3.4 \mathrm{~A}$. in the $z$-direc tion. We have assumed an angle of $36^{\circ}$ between adjacent residues in the same chain, so that the structure repeate sfter 10 residues on each chain, that is, after 34 A. The distence of a phosphorus atom from the fibre axis is $10 \mathrm{~A}$. As the phosphates are on the outside, cations have sasy gecess to them.

The atructure is an open one, and its water content is rather high. At lower water contents we would expect the bases to tilt of that the structure could become more compect.

The novel feature of the structure is the manner in which the two chains are held together by the purine and pyrimidine beaee. The planes of the beases are perpendiculat to the fibre axis. They are joined together in pairs, a single base from one ohain being hydrogen-bonded to a single base from the other chain, so that the two lie side by side with identioal $z$-co-ordinates. One of the pair must be a purine and the other a pyrimidine for bonding to occur. The hydrogen bonds are mesde as follows: purine position 1 to pyrimidine position 1 ; purine poeition 6 to pyrimidine position 6 .

If it is assumed that the bases only cocur in the structure in the most plausible tautomerio forms (that ig, with the keto rather than the enol configurations) it is found that only apecific peirs of beses can bond together. These pairs are : edenine (parine) with thymino (pyrimidine), and guanine (purine) with cytosine (pyrimidine).

In other words, if an adenine forms one momber of a pair, on either chain, then on these ascumptions the other member must be thymine; similerly for guanine and cytosine. The sequence of baees on a single chain does not sppear to be reetricted in any way. However, if only specifle pairs of beses cen be formed, it follows that if the pequenos of bases on one chsin is given, then the quence on the other chain is extornatically determined.

It has been found experimentallye, that the ratio of the amounts of adenine to thymine, and the ratio of guanine to cytosine, are elways very close to unity for deoxyriboso nucleic acid.

It is probsbly impossible to build this structure with a ribose sugar in place of the deoxyribose, se the extra orygen atom would make too close a van der Waals contact.

The previously published X-rey datass on dooxyriboes nucleic acid are insufficient for a rigorone teat of our structure. So far wo oan tell, it is roughly compatible with the experimental dats, but it must be regarded as unproved until it has been cheoked against more exact results. Some of these are given in the following communications. We were not sware of the delsils of the results preeented there when we devised our struoture, which rests mainly though not entirely on published experimental date and stereochemical arguraente.

It has not esceped our notioe that the speoific peiring we have postulated immediately suggests a poesible copying mechanism for the genetic material

Full details of the structure, inolnding the conditions assumed in building it, together with a met of co-ordinater for the atoms, will be published elsewhere.

We are much indebted to Dr. Jerry Donohue for constant advice and criticism, expecially on interatomic distanoes. We have also been stimulated by a knowledge of the general nature of the unpublished experimental results and ideas of Dr. M. H. F. Wilkins, Dr. R. E. Franklin and their co-workers

Figura 20: Trabalho original de Francis Crick e de James Watson, de 1953, na revista "Nature". 


\section{Referências Bibliográficas}

[1] R. Ferreira (2003) A história da descoberta da estrutura do DNA, Ed. Odysseus, São Paulo. Brasil.

[2] R.D. Keines (1997) Steps on the path to the origin of species, J. Theor. Biol. 187, 461-471.

[3] W.J. Bock (2003) Ecological aspects of the evolutionary processes, Zool. Sci. 20, 279-289.

[4] Ciência Hoje: http://www.uol.com.br/ciênciahoje (consultada em 2003).

[5] E. Chargaff (1971) Preface to a Grammar of Biology, a hundred years of nucleic acid research, Science $172,637-642$.

[6] D. Laukacs (1982) Centenary of the death of Theodor Schwann, Orv. Hetil. 123, 864-866.

[7] Medicina de la primera mitad del siglo XIX. http://www.puc.cl/ (consultada em 2004).

[8] B. Dawes (1952) A hundred years of Biology, Ed.Duckworth, London. U.K.

[9] A. Sturtevant (2001) A History of Genetics, Cold Spring Harbor Press, New York. U.S.A.

[10] DNA from the beginning: http://www.dnaftb.org/dnaftb/concept_8/con8bio.html\#sutton (consultada em 2004).

[11] Os primeiros trabalhos com Drosophila melanogaster. http://dreyfus.ib.usp.br/bio201/texto9.pdf (consultada em 2004).

[12] Nobel Museum: http://www.nobel.se/cgi_bin/laureates (consultada em 2002).

[13] R. Haussmann (1997) História da Biologia Molecular, Ed. Sociedade Brasileira de Genética. Ribeirão Preto. Brasil, pp. 70-91.

[14] B. Lewin (2001) Genes VII, trad. Henrique Ferreira (et al), Ed. Artmed. Porto Alegre. Brasil, pp. 4-5. [15] The Rockefeller University: http://www.rockefeller.edu/archive.ctr/ru-patl.html (consultada em 2003).

[16] Columbia University: http://cpmcnet.columbia.edu/neWs/in-vivo. (consultada em 2003).

[17] P. Reichard (2002) Osvald T. Avery and the Nobel Prize in Medicine, J. Biol. Chem, 277, 1335513362 .

[18] A. Klug (1968) Rosalind Franklin and the discovery of the Structure of DNA, Nature 219, 808-810.

[19] E. Schrödinger (1997) O que é vida? O aspecto físico da célula viva, seguido de mente e matéria e fragmentos autobiográficos, Ed. Unesp. Cambridge University Press. São Paulo. Brasil, pp. 67-72.

[20] A. Klug (1974) Rosalind Franklin and the double helix, Nature 248, 787-788.

[21] J.D Watson, F.H.C. Crick (1953) Molecular Structure of Nucleic Acids, A Structure for Deoxyribose Nucleic Acid, Nature 171, 737-738.

[22] J.D. Watson, F.H.C. Crick (1953) Genetical implications of the Structure of Deoxyribonucleic Acid. Nature 171, 964-967.

[23] Revista Biotecnologia, Ciência e Desenvolvimento. http://www.biotecnologia.com.br/800.html (consultada em 2003). 